\title{
Automated system-cognitive analysis of the dependence of export and import of agricultural machinery on its production (the case of Russia)
}

\author{
Ksenia A. Semenenko*, Eugeny V. Lutsenko, Irina V. Snimshchikova, and Valery I. Loiko \\ Kuban state agrarian University named after I. T. Trubilin, Krasnodar 350004, Russia
}

\begin{abstract}
The issue raised in the article is the study of the dependence of export and import of agricultural machinery on its production in Russia. The Russian agricultural machinery market is influenced by three groups of factors: 1) own production of agricultural machinery; 2) export of agricultural machinery of Russian production; 3 ) import of agricultural machinery of foreign production. Traditionally, such problems are solved using multivariate analysis. However, in this case, the use of this method is problematic for a number of reasons: the source data is dimensional and measured in different units, the number of observations is less than the number of factors, the factors depend on each other, and the number of factors is too large. These restrictions are proposed to be overcome by applying automated system-cognitive analysis and its software tools of the intellectual system "Eidos". For this purpose the following tasks were solved: 1) formulation of the idea and the concept of problem solving; 2) justification of the choice of the method and tool for solving the problem; 3) application of the selected method and tool to solve the problem; 4) evaluation of the effectiveness of the proposed solution of the problem; 5) consideration of the restrictions and disadvantages of the proposed solution of the problem and the prospects for its development by overcoming these restrictions and disadvantages. Some results of solving these problems are briefly summarized in this article.
\end{abstract}

\section{Introduction}

The problem solved in the article is the study of the dependence of export and import of agricultural machinery on its production in Russia. The market of agricultural machinery in Russia is influenced by three groups of factors:

1) Own production of agricultural machinery in Russia (this group includes 8 factors);

2) Export of agricultural machinery of Russian production (19 factors);

3) Import of agricultural machinery of foreign production (24 factors).

Thus, the object of modeling is described by 51 factors. Traditionally, such problems are solved by statistical methods, in particular, multivariate analysis. Factor analysis imposes strict requirements on the source data, which in practice is very difficult to provide.

However, in this case, the application of this method is problematic for a number of reasons: the initial data are dimensional and measured in different units: own production of agricultural machinery in Russia is measured in physical terms by type of equipment, and export and import are measured in terms of value; the number of observations ( 8 years) is less than the number of factors; all these factors depend on each other; the number of factors is generally too large; all combinations of factor values should be presented in the initial data; the data should be absolutely accurate, etc.

It is proposed to overcome all these restrictions by using the automated system-cognitive analysis (ASCanalysis) and its software tools of the "Eidos" intelligent system, which do not impose special requirements on the source data and work with the data that the researcher actually has at the disposal. For this purpose, it is necessary to solve the following tasks:

Task 1: to formulate the idea and the concept of problem solving;

Task 2: to justify the choice of the method and tool for solving the problem;

Task 3: to apply the selected method and tool to solve the problem, i.e. to perform the following steps: cognitive structuring of the subject area; formalization of the subject area; model synthesis and verification; improving the quality of the model and the selection of the most reliable model; decision-making in the most reliable model of diagnostic tasks (classification, recognition, identification), decision support and study of the modeled subject area by examining its model;

Task 4: to evaluate the effectiveness of the proposed solution of the problem;

Task 5: to consider the restrictions and disadvantages of the proposed solution of the problem and the

* Corresponding author: ksenia.semenenko@gmail.com 
prospects for its development by overcoming these restrictions and disadvantages.

Below we briefly consider the solution of these problems.

\section{Materials and Methods}

\subsection{The idea and the concept of problem solving (task 1)}

The idea of solving the problem is to apply for this purpose a modern innovative method of artificial intelligence, which simply did not exist during the development of the traditional approach.

Concept of problem solving: to solve the problem, we need a method of quantitative detection in comparable form of the force and direction of cause-andeffect dependencies in incomplete noisy data of very large dimensions of numerical and non-numeric nature, measured in different types of scales and units.

\subsection{Justification of the choice of method and tool for solving the problem (task 2)}

There are many methods and systems of artificial intelligence. But the automated sys-tem-cognitive analysis and its software tools, the "Eidos" intellectual system, differ from them in the following parameters:

- It is developed in a universal setting that does not depend on the subject area. There-fore, it is universal and can be applied in many subject areas (http://lc.kubagro.ru/aidos/index.htm);

- It is in full open free access (http://lc.kubagro.ru/ aidos/_Aidos-X.htm), and with the current source code (http://lc.kubagro.ru/_AIDOS-X.txt);

- It is one of the first Russian systems of artificial intelligence of the personal level, i.e. it does not require special training from the user in the field of artificial intelligence technologies (there is an act of implementation the "Eidos" system of 1987) (http://lc.kubagro.ru/aidos/aidos02/PR-4.htm);

- It provides a stable identification in a comparable form of force and direction of cause-and-effect dependencies in incomplete noisy interdependent (nonlinear) data of very high dimensionality of numerical and non-numerical nature, measured in various types of scales (nominal, ordinal and numerical) and in different units of measurement (i.e. it does not impose strict data requirements that cannot be fulfilled, but processes the data that are available);

- It contains a large number of local (supplied with the installation) and cloud educational and scientific applications (currently there are 31 and 144, respectively) (http://lc.kubagro.ru/aidos/Presentation_ Aidos-online.pdf);

- It provides multilingual interface support in 44 languages. Language bases are included in the installation and can be updated automatically;
- It supports online knowledge accumulation environment and it is widely used throughout the world (http://aidos.byethost5.com/map5.php);

- The most computationally intensive operations of model synthesis and recognition are implemented using a graphics processor (GPU), which in some tasks accelerates the solution of these tasks several thousand times, which actually provides intelligent processing of big data, big information and big knowledge;

- It provides the transformation of the initial empirical data into information, and information - into knowledge and decision using this knowledge of the tasks of classification, decision support and research of the subject area by studying its system-cognitive model, generating a very large number of tabular and graphical output forms (development of cognitive graphics), many of which have no analogues in other systems (examples of forms can be found in the work: http://lc.kubagro.ru/ aidos/aidos18_LLS/aidos18_LLS.pdf)

All this determines the choice of the ASC-analysis and the "Eidos" system as an instrument for solving the problem. This method has been successfully applied to solve a large number of problems in various subject areas [1].

\subsection{Application of the selected method and tool to solve the problem (task 3)}

Solution of task 3 involves the following steps, standard for ASC-analysis: cognitive structuring of the subject area; formalization of the subject area; model synthesis and verification; improving the quality of the model and the selection of the most reliable model; decisionmaking in the most reliable model of the tasks of diagnostics (classification, recognition, identification and forecasting), decision support and study of the modeled subject area by studying its model. All these stages of the ASC analysis, except the 1st stage, are automated in the "Eidos" system. Let us consider them in order of execution.

\subsection{Cognitive-targeted structuring of the subject area}

At the stage of cognitive-target structurization of the subject area, we decide on a qualitative level what we consider as factors acting on the object being modeled (causes), and what are the results of the action of these factors (consequences of their action). In this paper, we are going to estimate the volume of exports of this equipment from Russia and imports to Russia (in value terms) on the basis of knowledge of the volumes of agricultural machinery production in Russia (in natural terms). Respectively, to formalize the task performed in the next stage of the ASC-analysis, we will use the following measurement scales:

- classification scales (results of influence of factors): Import Germany, mln. US\$; Import Netherlands, mln. US\$; Import Belarus, mln. US\$; Import USA, mln. US\$; Import China, mln. US\$; Import Italy, mln. US\$; Import Finland, mln. US\$; Import 
Poland, mln. US\$; Import France, mln. US\$; Import Ukraine, mln. US\$; Import Canada, mln. US\$; Import Sweden, mln. US\$; Import Spain, mln. US\$; Import Czech Republic, mln. US\$; Import Denmark, mln. US\$; Import Hungary, mln. US\$; Import Belgium, mln. US\$; Import Austria, mln. US\$; Import Slovakia, mln. US\$; Import Turkey, mln. US\$; Import UK, mln. US\$; Import Argentina, mln. US\$; Import Romania, mln. US\$; Import Croatia, mln. US\$; Export Kazakhstan, mln. US\$; Export Belarus, mln. US\$; Export Ukraine, mln. US\$; Export Lithuania, mln. US\$; Export Mongolia, mln. US\$; Export Uzbekistan, mln. US\$; Export Germany, mln. US\$; Export Republic of Moldova, mln. US\$; Export Bulgaria, mln. US\$; Export Kyrgyzstan, mln. US\$; Export Poland, mln. US\$; Export Canada, mln. US\$; Export Turkmenistan, mln. US\$; Export Tajikistan, mln. US\$; Export Armenia, mln. US\$; Export Azerbaijan, mln. US\$; Export Georgia, mln. US\$; Export Latvia, mln. US\$; Export Turkey, mln. US\$.

- descriptive scales (factors): Produced in Russia tractors, units; Produced in Russia combine harvesters, units; Produced in Russia forage harvesters, units; Produced in Russia ploughs, units; Produced in Russia harrows, units; Produced in Russia seed drills, units; Produced in Russia mowers, units; Produced in Russia tractor cultivators, units.

\subsection{Formalization of the subject area and description of the source data}

The formalization of the subject area is the stage of the ASC-analysis, at which classification and descriptive scales and grades are first developed, and then using them, the initial data are coded to a form that is convenient for further processing in the "Eidos" system, i.e. for the synthesis and verification of models, i.e. an educational sample and a database of events are formed. In fact, the training sample is a normalized database of input data [2, 3].

There are many program interfaces with external data sources (API) in the "Eidos" system that can automate the stage of subject domain formalization. These interfaces can be combined into three groups: interfaces with text data; interfaces with tabular data; interfaces with graphic data. In this case, we used a universal software interface for entering data from external data sources 2.3.2.2.

As a result of the work of this software interface, classification and descriptive scales and gradations and a training sample have been created (Table 1). The full table of classification scales and gradations is not given, since there are 129 lines in it.

Thus, the formalization of the subject area is carried out and all conditions are created for performing the next stage of the ASC-analysis: synthesis and verification (assessment of reliability) of the models.

\subsection{Synthesis and verification of statistical and system-cognitive models}

\subsubsection{Model synthesis}

The synthesis and verification of models is carried out in mode 3.5 of the "Eidos" system. As a result of this mode, three statistical models (Abs, Prc1, Prc2) and seven system-cognitive models (SC-models: Inf1-Inf7) were created. But applying these models to solving problems is correct only if they are reasonably reliable for this. Therefore, verification of the created models is a necessary stage of the ASC-analysis.

\subsubsection{Model Verification}

The assessment of the reliability of the models is carried out by solving the problem of classifying objects of the training sample according to generalized images of classes and counting the number of true and false, positive and negative solutions according to the classical F-measure of van Rijsbergen [4], as well as prof. E.V. Lutsenko, which are fuzzy multiclass generalizations of van Rijsbergen measure, invariant with respect to the size of the training sample. In the 3.4 mode of the "Eidos" system we determined that, according to the L1-measure, the INF3 model has the highest accuracy that allows solving the most reliable SC-model Inf3 tasks posed in the work, the results of solving some of which we briefly consider below.

Table 1. Training sample (fragment)

\begin{tabular}{|c|c|c|c|c|c|c|c|c|c|c|c|c|c|c|c|c|c|c|c|c|}
\hline & $\tilde{z}$ & $\tilde{z}$ & $\stackrel{+}{Z}$ & ' & z & z & $\stackrel{\infty}{z}$ & $\hat{z}$ & $\frac{O}{z}$ & $\overline{\bar{z}}$ & $\frac{\tilde{z}}{\mathrm{z}}$ & $\frac{m}{z}$ & $\frac{\nabla}{z}$ & $\frac{n}{z}$ & $\begin{array}{l}0 \\
z\end{array}$ & $\hat{\mathrm{z}}$ & $\stackrel{\infty}{z}$ & $\vec{z}$ & 艺 & $\overline{\mathrm{Z}}$ \\
\hline 2010 & 3 & 4 & 7 & 10 & 13 & 16 & 19 & 24 & 1 & 4 & 7 & 11 & 13 & 17 & 19 & 22 & 26 & 29 & 32 & 35 \\
\hline 2011 & 3 & 6 & 9 & 11 & 14 & 17 & 19 & 24 & 3 & 6 & 7 & 12 & 14 & 18 & 21 & 23 & 27 & 30 & 33 & 36 \\
\hline 2012 & 3 & 5 & ( & 12 & 13 & 16 & 20 & 24 & 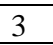 & 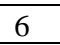 & 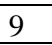 & 12 & 15 & 17 & 20 & 24 & 27 & 30 & 33 & 36 \\
\hline 2013 & 2 & 5 & 8 & 11 & 14 & 17 & 21 & 23 & 3 & 5 & 9 & 12 & 14 & 18 & 20 & 24 & 27 & 30 & 33 & 36 \\
\hline 2014 & 1 & 5 & 1 & 11 & 14 & 17 & 20 & 23 & 2 & 5 & 7 & 11 & 15 & 17 & 21 & 23 & 26 & 29 & 32 & 35 \\
\hline 2015 & 1 & 4 & 8 & 10 & 15 & 18 & 20 & 22 & 1 & 4 & 0 & 10 & 13 & 16 & 19 & 22 & 25 & 28 & 31 & 34 \\
\hline 2016 & 2 & 6 & 9 & 12 & 15 & 18 & 21 & 23 & 1 & 5 & 8 & 10 & 14 & 16 & 20 & 23 & 25 & 28 & 31 & 34 \\
\hline 2017 & 2 & 6 & 8 & 12 & 15 & 18 & 21 & 22 & 2 & 6 & 8 & 11 & 15 & 18 & 21 & 24 & 26 & 29 & 32 & 35 \\
\hline
\end{tabular}

\section{Results}

As a result of the research and development, models have been created that correctly reflect the causal relationships between the factors and the results of their influence in the modeled subject area, and, therefore, these models can be correctly used to solve the problems posed in the work. Below we briefly review the solution in the most reliable model of diagnostic tasks 
(classification, recognition, and identification), decision support and research of the modeled subject area by examining its model.

\subsection{Solution of the problem of classification and forecasting}

The results of forecasting the volume of exports and imports in 2017 fully coincide with the fact volumes.

\subsection{Decision-making and decision support}

Figure 1 presents the SWOT-diagram showing the influence of the volume of agricultural machinery production in Russia on the maximum volume of imports from the Netherlands.

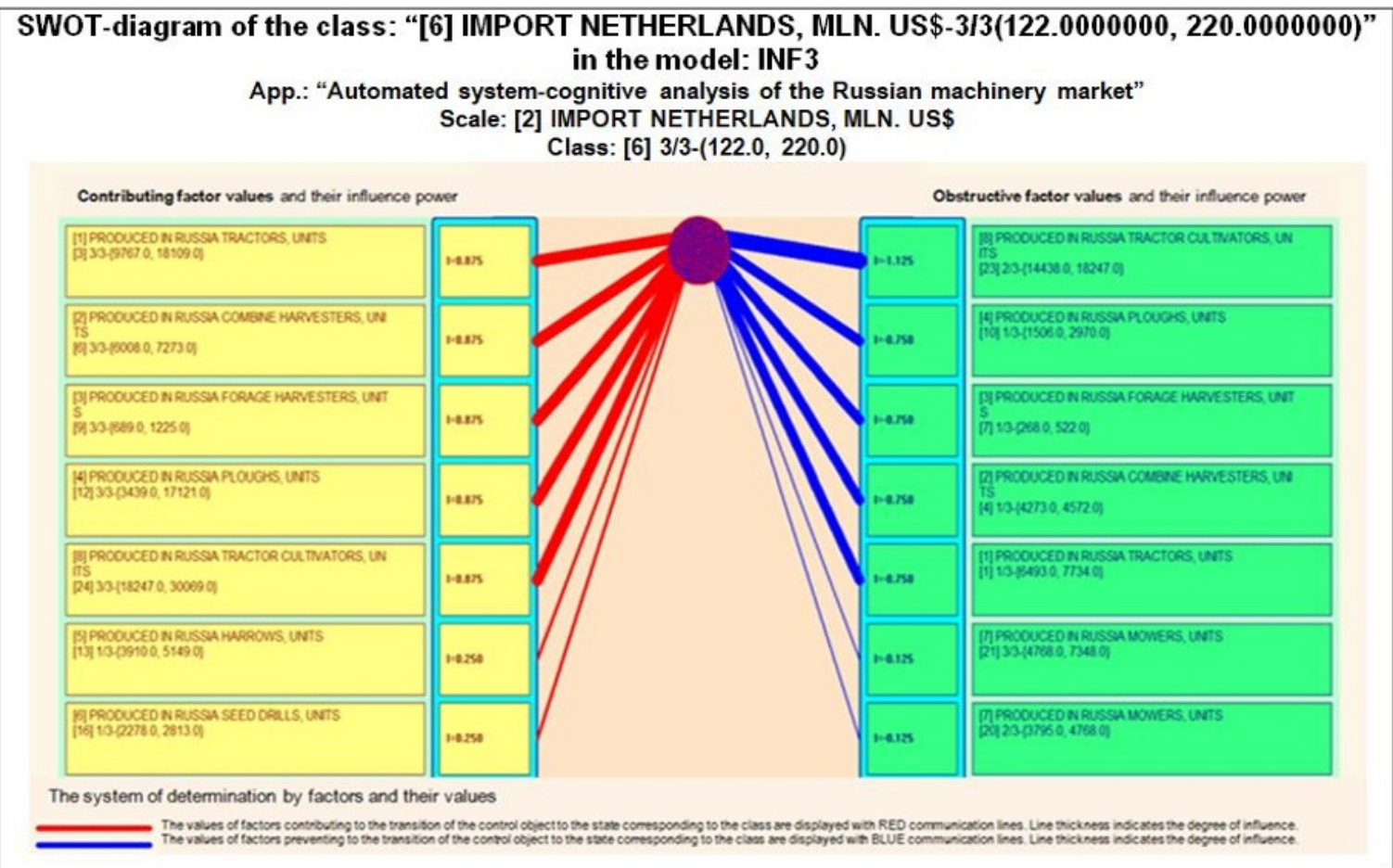

Fig. 1. SWOT-diagram showing the impact of agricultural machinery production in Russia on the maximum volume of import from the Netherlands

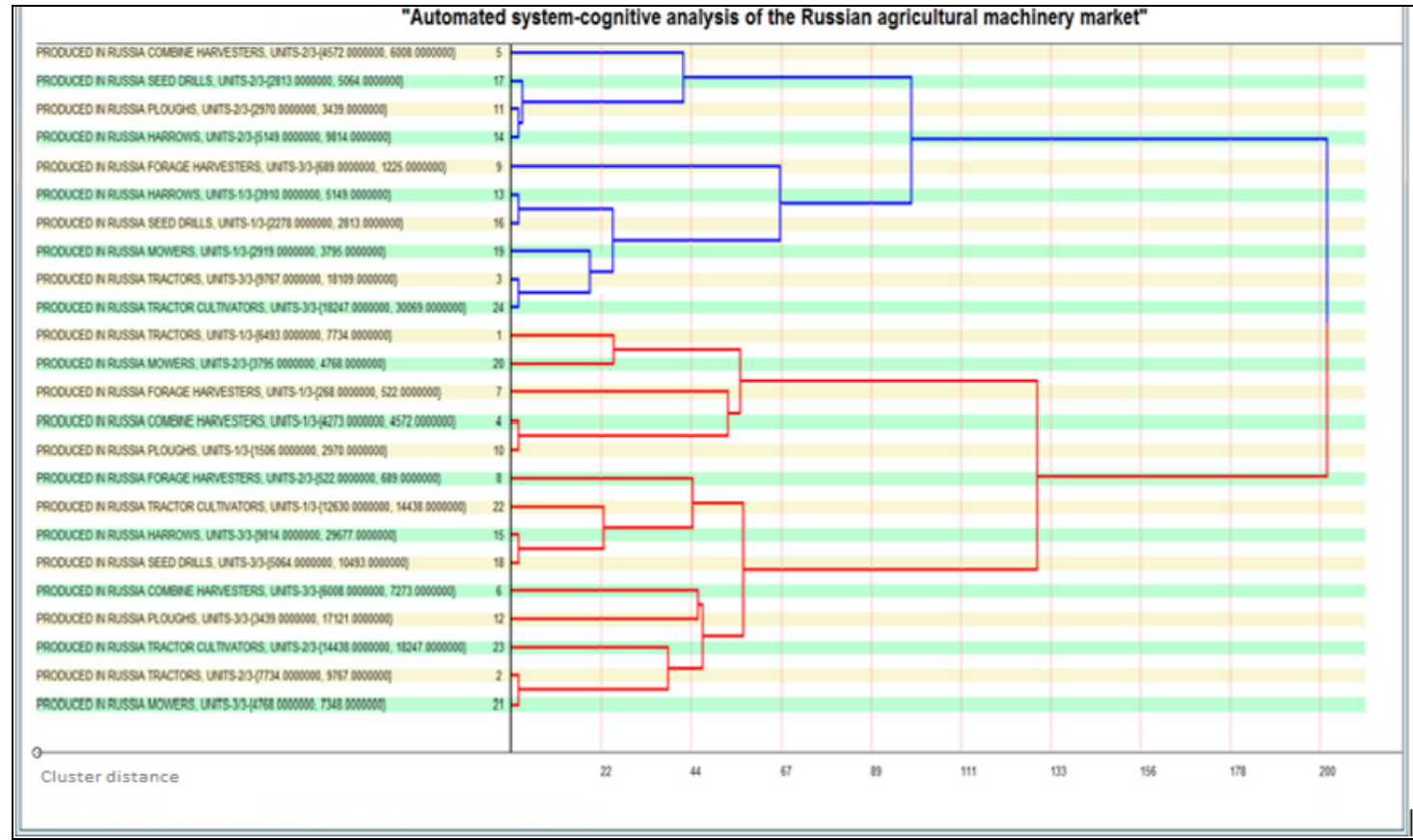

Fig. 2. Results of cognitive clustering of classes 


\subsection{Studying the modeled subject area through the examination of its model}

The "Eidos" system includes many different possibilities for studying a modeled object by examining its model. The results of these studies can be considered as the results of the study of the object of modeling itself only to the extent that the model correctly reflects its properties, in which it is adequate. In particular, these are the following research possibilities: non-local neurons and a neural network; cognitive diagrams of classes and factor values; automated cognitive SWOT-analysis; cognitive functions and a number of others, cognitive agglomerative clustering of classes and values of factors and a number of others. Let us consider some of them. In
Figure 2, we see the results of a cognitive clustering of factor values [5].

Figure 3 shows a Pareto-subset of a non-local neural network in an Inf3 model. The dependence of the values of the output indicators from the values of the acting factors we see on cognitive functions [6], one of which is shown in Figure 4.

We can receive 344 such cognitive functions, reflecting the impact of the production of various types of agricultural machinery in Russia ( 8 factors) on the volumes of export and import of agricultural equipment from various countries (43 indicators).

Cognitive functions reflect in color the amount of information we get from a certain value of a factor that the system under its influence changes to a state corresponding to various classes.

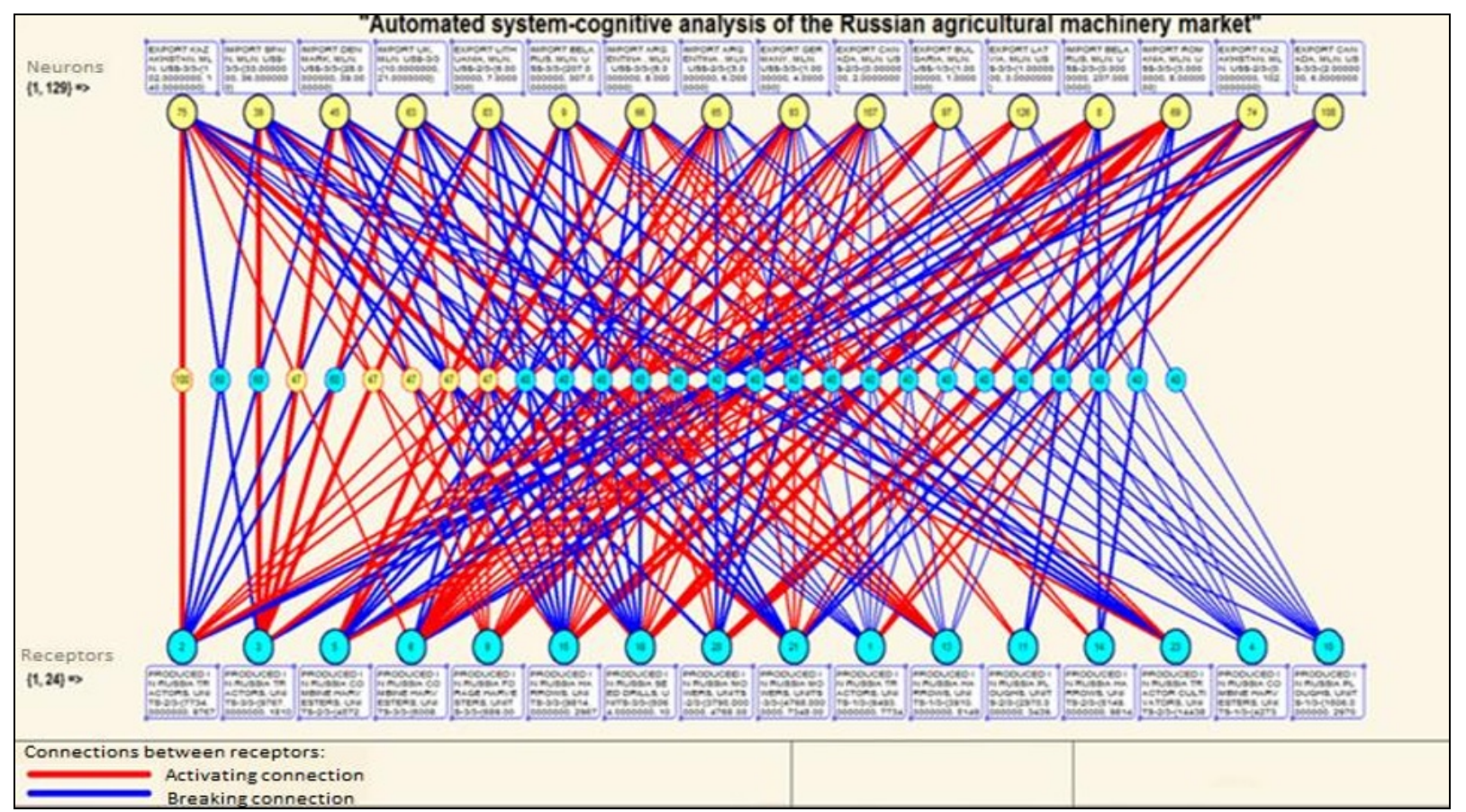

Fig. 3. Pareto-fragment of a non-local neural network in the Inf3 SC-model

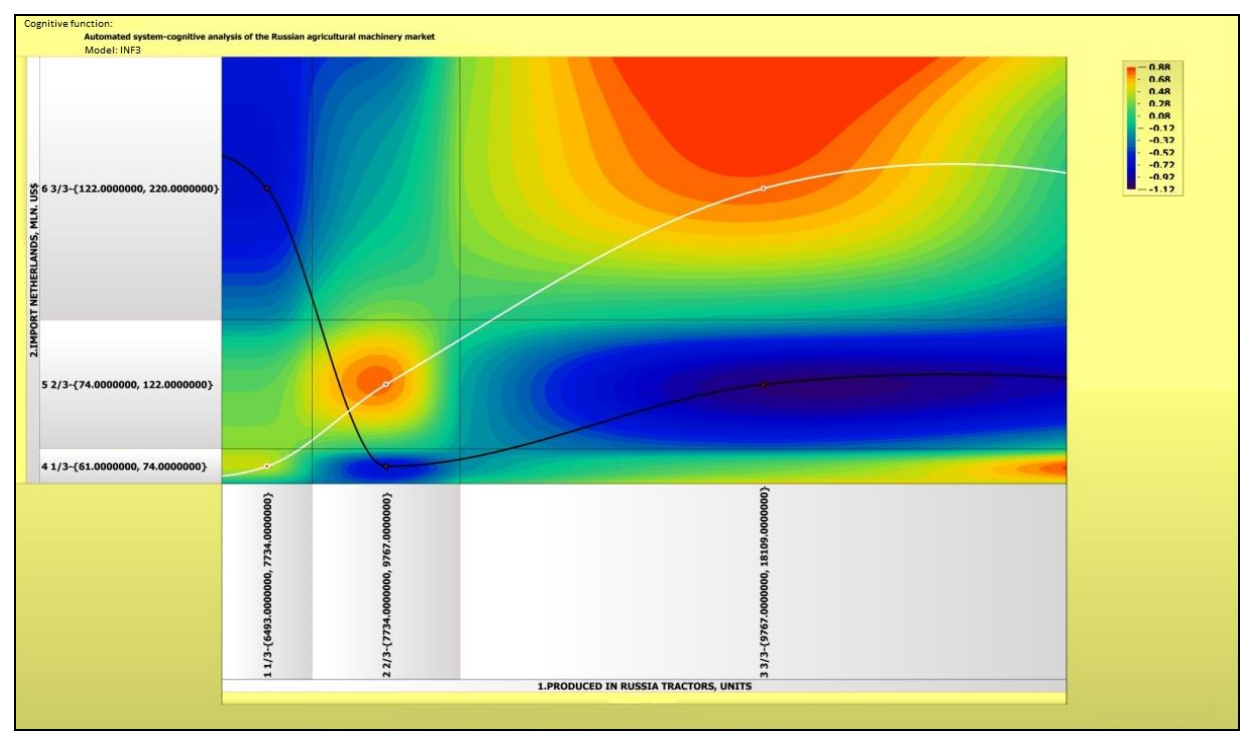

Fig. 4. Cognitive function, reflecting the impact of tractor production in Russia on the import of agricultural machinery from the Netherlands, SC-model Inf3 


\section{Conclusion}

On the basis of the conducted research the following conclusions can be made:

1. In Russia, the needs of agricultural producers in agricultural machinery are not covered by domestic production. At the same time, it is impossible to talk about direct dependence on foreign manufacturers and import, since the market of agricultural equipment is affected by a set of factors, among which are the financial possibilities of consumers / producers of agricultural machinery, namely, their demand/supply, as well as changes in the quality of the produced machinery, which leads to an increase in the service life; and internal cooperation of production with the CIS countries, which also changes the market $[7,8]$.

2. The reduced production volumes occur synchronously with the reduction of export and import, which indicates a decrease in the economic activity of the market as a whole. Import of agricultural machinery from other countries does not compensate for the lack of production capacity.

3. The export of agricultural machinery from Russia is increasing due to the mechanisms of state support, improvement of the quality of the produced equipment and an affordable price. In most cases, export deliveries are made to countries where production is based on processing large spaces with a relatively small amount of heavy equipment $[9,10]$.

\subsection{The effectiveness of the proposed solution of the problem (task 4)}

As the analysis of the results of system-cognitive modeling shows the solution of the proposed tasks and implemented in the "Eidos" system is quite effective that makes it reasonable to say that the goal of the work has been achieved.

\subsection{Restrictions and disadvantages of the proposed solution of the problem, prospects (task 5)}

The results are obtained on a limited amount of data in just 8 years. At the same time, the influence of 8 factors describing the production of agricultural machinery in Russia in physical terms was studied on 43 indicators characterizing the export and import of agricultural equipment in value terms. Of course, it is desirable to increase the number of observations, perhaps by breaking them down into quarters or months. It is planned to do this in future.

According to the results of the study, it is possible to make a reasonable conclusion that all the tasks have been solved, the goal has been achieved, and the problem has been solved.

\section{References}

1. E.V. Lutsenko, Intelligent scalable open interactive online environment for teaching and researching on the basis of ASC-analysis and "Eidos" system Sci. J. of KubSAU 6(130), 1-55 (2017)

2. Uncomtrade analytics, Retrieved from: https://comtrade.un.org

3. Statista - The portal for statistics, Retrieved from: https://www.statista.com

4. B. Ma, Q. Wei, G. Chen, A combined measure for representative information retrieval in enterprise information systems J. of Enterprise Informat. Management 24(4), 310-321 (2011)

5. I.S. Akila, R. Venkatesan, A Cognitive Multi-hop Clustering Approach for Wireless Sensor Networks Wireless Personal Communicat. 90(2), 729-747 (2016)

6. P.S. Pavlov, Methods of assessment of the quality of recommendations systems Int. J. of Humanities and Natural Sci. 6(1), 178-182 (2018)

7. Global Agricultural Machinery Market 2016-2020, Retrieved from: https://www.researchandmarkets.com

8. High growth for European tractor market in 2017, Retrieved from: http://www.cema-agri.org.

9. K.A. Semenenko, T.K. Becker, The level of dealer's satisfaction with the producers of agricultural machinery: German experience Sci. J. of KubSAU 114(10), 1-14 (2015)

10. G. Dryancour, The Agricultural Machinery Market \& Industry in Europe: An analysis of the most important structural trends \& why EU regulation of the sector needs to change (CEMA, 2016) 